\title{
IMPACT OF E-COMMERCE TOWARD INDONESIAN Silk INDUSTRY : The ChangING VALUE CHAIN OF SMALL MEDIUM ENTERPRISE IN SOUTH SULAWESI MUNICIPALITIES
}

\author{
Prof. Dr. Haris Maupa, S.E., M.Si. \\ Professor in Small Medium Enterprise and Management \\ Head,Doctors Programsin Economics, Management and Accounting in \\ Post-Graduate Program (http://pasca.unhas.ac.id) at Hasanuddin University \\ (http://www.unhas.ac.id/en), Indonesia.
}

\begin{abstract}
The advent of the internet and information technology has revolutionarized the way small medium enterprise do business, particularly those that in the silk industry. This preliminary research will look at the definitions of e-commerce by various authors including Turban et al (2002) and Nezu (2001). A definition of commerce will be suggested that takes into account all the areas in e-commerce including business-to-business e-commerce and intrabusiness e-commerce which are usually not mentioned in many definitions of e-commerce.The new types of products i.e. digital products as well as the new business models which include content, affiliate and customization will be mentioned. The impact of technology on the value chain in particular disintermediation and cybermediation with relevancies from the Indonesian Silk Industry will be discussed.The theory of Diffusion of Innovation will be stated used to understand the evolution of the internet and the adoption of web technologies by SME.Finally, the future of e-commerce which includes the lessons learnt from start-up failures and the way that click-and-mortar industries can be successful will be discussed.
\end{abstract}

\section{KEYWORDS}

E-commerce,small medium enterprises, disintermediaries, cybermediaries, silk industry

\section{INTRODUCTION}

The advent of the internet and information technology has revolutionarized the way small medium enterprises (SME)in the Creative Industries do business. Over the past two decades, trade in creative industries has grown rapidly: the totalvalue of trade grew from 47.8 billion USD in 1980 to 1.3 trillion in 2005 (Singh 2007).This preliminary research will look at the use of Ecommerce in one particular Creative Industry and its impact on the value chain of remote Small Medium Enterprises in the Silk Industry in the municipalities located in South Sulawesi Province of Indonesia.

A definition of commerce will be suggested that takes into account all the areas in e-commerce including business-to-business e-commerce and intrabusiness e-commerce which are usually not mentioned in many definitions of e-commerce.The new types of products i.e. digital products as well as the new business models which include content, affiliate and customization will be mentioned. The impact of technology on the value chain in particular disintermediation, reintermediation and cybermediation with examples from this particular industry.

The theory of Diffusion of Innovation will be stated used to understand the evolution of the internet and the adoption of web technologies by SME .Finally, the future of e-commerce which 
includes the lessons learnt from start-up failures and the way that click-and-mortar industries can be successful will be discussed.

Natural silk fabric weaving have been acknowledged as one of the Creative Industries that being developed in the Eastern Provinces of Indonesia.

The importance of silk industry particularly in the area of South Sulawesi as it can add value have been recognized by the Provincial Government with Governor Decree No.1124/X/1992 on 8 October 1992. Since then, economic policy have been synchronized to develop silk industry in South Soulawesi that in turn have spurs a substantial market opportunity. This study aims to identify and analyze the influence of E-commerce to the processing of information and its impact on purchasing decisions of SME in the silk industries. The population in this study is the population is the entire SMEwithin the Municipality of Makassar, Municipality of Pare-pare, Municipality of Bone and Municipality of Wajo. These municipalities have the largest share of silk production value in accordance with the data Dinas Perindustrian dan Perdagangan as the subset of Ministry of Indonesian Industry from 2010 to 2014.

\section{THEORETICAL CONSIDERation}

What is e-commerce?There are several definitions of e-commerce. In fact e-commerce is synonymous with e-business and they are used inter-changeably. Nezu (2001) define ECommerce as it as "any method of using electronic communications and computer technology to conduct business.". However these definitions fail to capture the essence of e-commerce and the types of transactions carried out electronically.

Turban, King, Lee, Warkentin \& Chung (2002) define e-commerce from various perspectives. Some of these perspectives include the service perspective which views Electronic Commerce (EC) as a tool that addresses the desire for firms, consumers, and management to cut service costs while improving the quality of goods and increasing the speed of service delivery; the collaboration perspective which views EC as a framework for inter- and intraorganizational collaboration; and a community perspective which views EC as providing a gathering place for community members, to learn, transact and collaborate.

This definition defines e-commerce in more detail, taking into account the exchange of business information, "soft merchandise" and business-to-business transactions as well the buying and selling goods and services on the Internet.After looking at the definitions presented above, a definition of e-commerce should contain the following elements including, the buying and selling of goods and services, the exchange of information, the servicing of customers, the collaboration of business partners, electronic transactions within organizations, business-tobusiness transactions and exchange of soft merchandise via computer networks like the Internet.

Electronic commerce is indeed a revolution. It has changed the way business is conducted in particular, the emergence of electronic marketplaces with new types of products and services; new business models; new distribution channels; and new legal and regulatory frameworks. This is all due to the evolution of Information Technology. In fact Turban et al (2002) refers to the emergence of the digital economy which is based on digital technologies like digital communications networks (like the Internet, intranets), computers, software, and other related information technologies. Turban et al (2002) goes on further to define digital economy as the convergence of computing and communications technologies through the Internet and the resulting flow of information and technology that is stimulating EC and spurring vast organizational changes and business models.

The new business models that the Internet has brought are: 
1. Brokerage;according to (Novak \& Hoffman 2001), the brokerage model brings buyers and sellers together to encourage transactions. Brokerage models were primary thought of as $\mathrm{B} 2 \mathrm{~B}$, they can also be $\mathrm{B} 2 \mathrm{~B}, \mathrm{C} 2 \mathrm{C}$. The revenue stream for such a model is primarily a collection of a transaction fee, but other sources are possible like advertising, subscriptions, or sponsorship. An example of a website with this sort of model is Google Business which owns and operates vertical marketplaces that unite buyers and sellers from around the world by catering to individuals with similar professional interests like healthcare, food service, artistic product, et cetera.

2. Content; many websites on the internet are based on the provision of content. New sites, online magazines, product information and review sites are all content sites. Examples of content sites are the popular portal Yahoo.com which now has paid content. According to Nelson (2003), Yahoo! provides a level of free service to its customers but consumers pay for enhanced content and tools. Some of Yahoo!'s best performing paid products have been extra storage for Yahoo! mail; online games and tournaments; and Yahoo! Personals. Its newest paid content model is the Yahoo! Platinum service has been live since March 2003 and provides users with a range of text, video and audio content across news, sports and entertainment areas-all provided by major third party publishers.

3. Search; Novak \& Hoffman (2001) highlight the fact that searching for information is one of the most important services to provide consumers on the Web. In early portals like yahoo, at their base are companies made from helping to locate information. The search category also includes recommender systems as this also helps customers locate products or information that otherwise they would not have been able to find. Search engines usually employ the following pricing models to gain revenue fro their searching activities, one-time flat rate, monthly fixed fee, pay-per-click, pay-per ranking and revenue sharing.. An Example is Google.com. According to Novak \& Hoffman (2001), this is one of the few remaining pure search engines-most have evolved into portals. Google.com claims to index over a billion Web pages.

4. Incentive; Novak \&Hoffman (2001) note that there are a number of incentives schemes on the internet. They usually give the customer the option of accumulating "points" or other incentives that will be useful to the customer later. By rationing out the "points", it is possible to mould the behaviour of the customer. An example is it is possible to provide referrals to other companies that also accept the "points". These incentives can be seen as some sort of unofficial currency in that they have specific value attached to them. Novak \& Hoffman (2001) give the example of mypoints.com. Customer can join free of charge and gain 50 free points. Thereafter, a consumer can then gain points from performing "ordinary" online activities like visiting a website and interacting with online businesses. The consumer redeems their points for air travel, fine dining, merchandise and more from mypoints partners like Kmart, Barnes \& Noble Booksellers, Marriott, Macy's, Hollywood Video, and the Olive Garden and many more.

5. Communications; Novak \& Hoffman (2001) note that communication is an important source of customer value. Communication in particular e-mail is why people go to the Internet in the first place. Some companies have taken advantage of this need and moved into the space with products. Portals like yahoo.com, google.com all have free e-mail services. All one needs to do is register with them, get a user account, obtain a free email address and free e-mail storage space up to a certain amount. Also Internet Service Providers like Indosat and Telkom provide consumers with a way of connecting to the internet. The services offered include access to the web either through simple dial-up, 
broadband or Digital Subscriber Line (DSL); an e-mail account with more than one email address. The pricing models in this area are largely free trial offers followed by flatrate prices. Other communications on the web include computer-to-phone communications. An example is Skype which allows free computer-to-phone phone calls w using a headset plugged into one's PC, and low priced international calls from PC to phone.

6. Control; Novak \& Hoffman (2001) note that the web increases a customers control however it also creates the problems involving customer privacy, objectionable content and proprietary content. Websites like Anonymizer.com which uses a subscription revenue model to allow a user to disguise their Web visits and identity.

7. Customization and personalization; Turban et al notes that this is not a particularly new business model. What is new is the ability to quickly customize and personalize products for consumers at prices just above their non-customized counterparts. An example is Dell computers which allows customers to order custom made computers on its website and delivers the customized product right to their doors.

8. Affiliate; Novak \& Hoffman (2001) notes that this model provides value to small websites that seek to be advertiser supported yet lack the traffic clout to generate any advertiser's interest. In the affiliate model, a website participates in "affiliate programs" of transaction sites such as amazon.com or cdnow.com. Novak \& Hoffman (2001) go on to say that the affiliates place links or ads on their websites and are rewarded a referral fee if the customer clicks on their link and purchases goods on that transaction site. This is actually the pay-per-performance revenue model, i.e. if the consumer goes to the transaction website and buys nothing then the affiliate does not get any fee. This model was developed by CDNOW.

9. Name your price; Turban et al (2002) notes that model was pioneered by priceline.com. This model allows a buyer to set a price he/she is willing to pay for a product or service. Priceline.com will then try to link this customer to a supplier willing to sell that product or service at that price.Customer may have to submit several bids before they can get that product or service.

10. Online Auctions; One of the largest online auction sites is e-bay.com Other companies that carry out online auctions include Amazon.com and Yahoo.com.Many websites employ more than one business model. For example yahoo uses content, online auctions, content, affiliate marketing to generate revenue.

\subsection{Diffusion of Innovation}

Frith (2000) defines the diffusion of innovation as a notion which characterizes the spread of new technologies, products and services, whether tangible or intangible to society. Frith also notes that the increasing rate of consumer adoption can be attributed to in some part to increasing globalization and the relative wealth currently enjoyed by developed nation.

The Diffusion of innovation theory according to Rogers describes 4 main elements. These are the innovation itself; communication which is the process of the new idea traveling from one person to another or from one channel to the individual; the social system which is the individuals that together complete a specific goal (adoption) and Time which is how long it takes for a group or individual to adopt innovation. 
Also Adopters of innovation generally fall into one of a number of categories (Rogers). Frith (2000) goes on to add that the adopters which make up each category vary in terms of both their volume, time of adoption and social demographic. The five main categories are the Innovators, Early Adopters, Early Majority, Late Majority and Laggards. Innovators are willing to try new ideas, face the consequences of failure and realize that they are taking a risk. Innovators are usually well educated and have a high enough income to absorb mistakes.

- Early Adopters are again well-educated and wealthy, carry more respect and are more visible among their social groups. Early adopters are looked on for providing information about the innovation to others.

- Early Majority do not take such a huge risk as the previous category but accept the innovation before the average population.

- Late majority have limited wealth and income and are not willing to take the risk. They wait until others have widely adopted the technology.

- Laggards are usually skeptical of all new ideas. They often adopt an innovation as another is taking its place. They have overall the lowest wealth and education status and are surrounded by other laggards in society.

According to (Rogers, 2001), Interactive communication technologies like the internet were developed in the United States and other industrialized nations and spread rapidly in the 1990's in North America and Europe.

Rogers (2001) notes that the rate of adoption of the Internet and the World Wide Web is these settings may represent the fastest rate of adoption in the history of humankind has ever seen. This is because, the perceived attributes of the innovation are that it has considerable relative advantage over communication channels that is replaces for example the internet is cheaper, faster and better compared to the telephone, postal orders or telegrams. Using the internet is not particularly complex, if a person is already has access to a computer.Rogers also notes that the rate of adoption of the internet formed the classic S-curve that characterizes most diffusions of innovations

In a study conducted on the Fortune 100 and the internet in 1997 by Erik Tamplin et al, found that in the general averages of web innovation adoption, suggest that Technology companies (TEC) had a higher adoption rate of web innovations than the non-technology companies (nonTEC). The companies in the telecommunications, electronics and computer industries have a higher tendency to be innovative on their websites. These companies whose business falls into the primary information sector should be more ready to adopt internet technologies than those in the secondary information sector.

Further this study noted that the telecommunications, computer and electronic industries tend to be early adopters of Internet communication. This is because these individual organizations are among the first to try out an innovation. They also have a high degree of innovativeness which is the degree to which an individual or other unit of adoption is faster in adopting new ideas than other members of a social system in Williams, Rice, Rogers (1985, cited in Tamplin et al, 1997). Also Innovation laggards noted by Rogers (1995, cited in Tamplin et al, 1997) were those companies that did not have a URL domain name yet established. It was reasoned that Innovative Laggards should not be within the telecommunications, computer and electronic industries because of their innovative natures.

So what are the implications for companies that do not have the technology required to be on the internet? Perhaps companies should either acquire technology companies or form strategic 
alliances with them. An example is America Online (AOL) took over Netscape.com, one of the world's leading internet browsers.

Also many purely brick-and-mortar industries should participate in e-business or be left alongside the Super Highway like road kill. (Mackey 2003)

Mackey (2003) notes that e-business was preceded by the growth of the Internet in two phases: The communication phase and the Information Phase. The communication phase can be defined as the rapid adoption of e-mail. From AOL "carpet approach CD in the mail, CD at Target. This marked a period where e-mail and Internet awareness infectiously, revolutionizing how people and business communicated.

Mackey (2003) continues to highlight that as the online communication grew, so did the desire to provide information and hence the Information Phase was born. "Brochure ware" websites that provided primary organizational and contact information was the hallmark of the Information Phase. Brochure ware gave way to web tools, software solutions that made information sharing two-way. From surveys to shopping carts, e-mail lists and chat services, websites became a way to interact with site visitors. Many tools were designed to gather demographic data to help build the dotcom revenue model. It looked like brochure ware had borne some resemblance to magazine layouts; it seemed that the advertising model should apply to the web.

Mackey (2003) then looks at the third phase of the internet which is the Distribution phase which we have already entered. The web is the only global channel where online businesses can communicate to customers, deliver product and services 24 hours a day, 7days a week and 365 days a year. The internet delivers "digital products". For some companies like Yahoo! which is a portal that provides content, e-mail services, web hosting, shopping, chat rooms, and their customers the Internet is the entire channel and the whole relationship exists over the web. The supply chain and selling chain are integrated on one mega channel.

Using Slovin formula with 10 percent error tolerated, then the sample size is obtained as many as 100 people. The method of analysis is the Chi-square test. The results show that advertising on the internet have a positive and significant impact on information processing and purchasing decisions SME products (Silk Industries) in South Sulawesi, but marketing via e-mail no significant effect on information processing and purchasing decisions. Processing of information has a positive and significant impact on purchasing decisions. So it can be concluded that marketing variables via e-mail less influence consumers in making purchasing decisions of information processing that does not happen.

\section{E-COMMERCE ImPaCt ON RURAL Silk Industry VALue Chain}

The advent and proliferation of the internet has changed business and marketing activities in particular distribution channels. The importance of the Internet as a medium for market transactions is rapidly increasing thereby supporting the development of interconnected marketplaces that facilitate the exchange of a wide variety of products and services as well as the exchange of information (Meck, 2000).

\subsection{Disintermediation and Re-intermediation}

According to Malone et al (1987, cited in Giaglis et al,) early research in electronic markets suggested that there would be gradual elimination of intermediaries from the value system. Disintermediation is the word used to describe the alleged move towards shorter value chains in electronic marketplaces. Intermediaries are defined as an agent or middleman who "coordinates 
the exchange of goods and services either by purchasing from suppliers for resale to buyers or by helping buyers and sellers to meet and transact."(Meck, 2001)

These intermediaries (wholesalers and retailers) are known to add significant costs to the value chain. This results in lower profits for the producers while at the same time, passing on higher final prices to consumers (Giaglis et al). With the use of E-Commerce such as email and adverstising on the Internet, there was therefore a strong incentive for both producers and consumers to drive intermediaries out of the value chain (Maupa et al, 2012).

The evolution of value chain looks something like this:

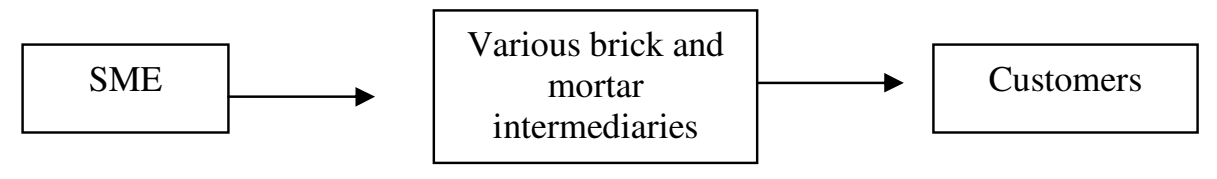

(a) Traditional silk industry value chain

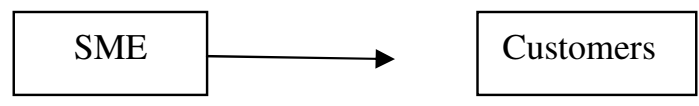

(b) Disintermediation insilk industry value chain

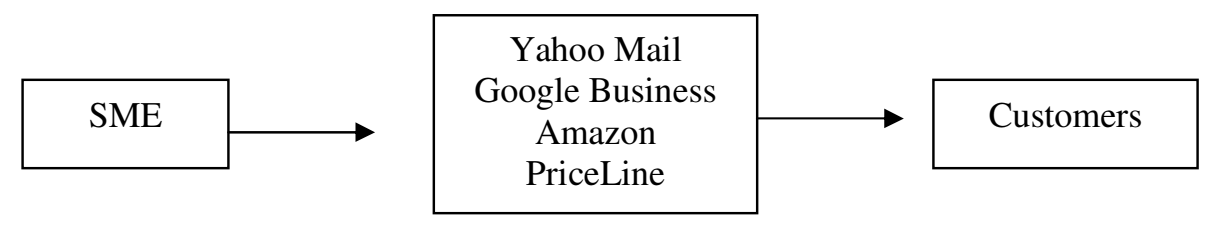

(c) Re-intermediation (cybermediaries) in silk industry value chain

Figure 1. Disintermediation, Re-intermediationand Cybermediaries in Remote Silk Industry Value Chain

The advanced uses of Information Technology and evolution of electronic marketplaces offers the opportunity for disintermediation as it allows producers or suppliers direct contact with consumers. This reduces the transaction costs for producers, thus enabling them to internalize activities that had to be purchased from the intermediaries in a traditional market. The resulting redistribution of profits can benefit from increasing their profit margins and passing a part of their savings to the consumers who thus enjoy lower prices and greater choice (et al). Further, Bailey\& Bakos (1996, cited in Giaglis et al) note that where one producer can dominate on price or quality, direct sales reduces the uncertainty of customers and a winner take all market will emerge

According to Giaglis et al, in the publishing industry traditionally books were sold through retail operations. The internet was initially hypothesized to substitute traditional retailers with electronic retailers. An example of an electronic retailer is Amazon.com. Further, it was suggested that publishers or authors or wholesalers would be able to gain direct access to consumer and hence changing the structure of the publishing value chain.

However this disintermediation hypothesis received considerable critique by Burton \& Mooney (1998, cited in Giaglis et al). This was backed by empirical observations that suggested the 
intermediaries, instead of disappearing, re-merged and gained considerable significance at least in electronic markets. Further, wholly new markets for electronic intermediaries or cybermediaries according to Sarkar et al (1995, cited in Giaglis et al) have been created.

Using the publishing example above, Giaglis et al notes that traditional retailers i.e. bookshops faced intense competition from e-tailers like Amazon.com. . Despite this, these traditional retailers differentiated themselves entered the market e.g. U.K. bookstore www.dillons.co.uk Furthermore publisher like www.springer.de are offering their products to consumers. Giaglis et al notes that disintermediation is limited so far but traditional retailers face increasing pressure from new entrants like Amazon who have successfully entered the market and developed innovative models of on-line retailing.

Also Giaglis et al also notes that while producers are able to sell directly to consumers in the electronic marketplace, lower barriers to entry and new market opportunities have in some cases actually increased the number of intermediaries.

\subsection{Cybermediaries}

Figure 1 also explicitly point to the birth of new cybermediaries in the silk industry value chain. Cybermediaries are new intermediation services that assist buyers and sellers in searching for relevant information and in matching customers with suppliers by filtering this information. (Meck, 2001). Meck (2001) goes on to suggest that these services are likely to become increasingly important in electronic market environments because they promise to offer the products that match the buyers' needs at the best price. In addition, purchases that are concluded over traditional bricks-and-mortar channels are also affected by increasing number of customers who use the internet as a source of product information as searching tool for goods.

Cybermediaries e.g. cybermall.com are like traditional malls as they provide infrastructure for the producer and a virtual 'mall' or place where consumers can browse through the different offers of merchants sorted by categories without having an already set idea of the product they are looking for. The source of income for these virtual malls is fees that they charge to their "renters" or the producers they provide infrastructure to. These virtual malls do not stock goods or sell products directly.

On the other hand virtual resellers obtain products directly from manufacturers, take an active part in sales by keeping their own stocks and by selling goods at their own profit. Websites like letsbuyit.com concentrate buyers in big lumps in order to exploit the bargaining leverage of buyers. This is known as Coshopping. Meck 2001 highlights the fact this these websites act as a purchasing cooperative. The discount or bargain price achieved depends on how many buyers sign up for a specific good within a fixed period of time.

Cybermediaries are also known to reduce search costs greatly by allowing consumers to compare items and compare prices all in one place, the internet and in many cases on one site. Search engines like Lycos.com and Infoseek.com provide users with the capabilities for conducting keyword searches of the extensive databases of websites.Directories like Yahoo! help consumers find producers by categorizing web sites and providing structured menus to facilitate navigation.Sites likes like Priceline.com match buyers with sellers who can provide a product at a price stated by the buyer.

According to Kephart \& Greenwald (2000, cited in Meck, 2001), intelligence agents also referred to as shopbots are software agents that automatically gather and collect information from multiple online vendors about prices and other attributes of consumer goods and services 
International Journal of Managing Value and Supply Chains (IJMVSC) Vol. 5, No. 4, December 2014

\subsection{The Future of E-Commerce for SME}

The dotcom crash of 2000 where many start up internet companies failed because they had as Mackey (2003) says "cocktail-napkin business plans". These companies did not have proper business plans and concrete ways of generating revenue, yet venture capitalists invested in them and the stock market inflated their values. This was because of the hype of the associated with ecommerce and how it was set to change business rapidly and the only way to be succeed in business was to have a start up internet company.

Merkow (2002) writes about Lessons learnt and Myths debunked from a book called The Death of e by Peter Finger and Ronald Aronica. This book debunks many myths about the e-commerce that have turned many fervent believers into dotcom road kill over the last 12-18 months. Merkow (2002) also notes from the book that the assumption that e-commerce requires a unique business model is ripped to shreds and reconstructed with the vision that sees e-commerce as an enabler to end-to end processing that just so happens to use automation and automated techniques.

Some of the myths and lessons learned that Merkow (2002) highlights are (1) "Clever ideas make new wealth". Lesson learnt: Without a sound business model that adds value, even the best ideas will not survive for long;(2)"The need for speed is central to the competitive advantage in the internet age" (Lesson Learnt: Time to market will not make up for poor or faulty business models); (3) Build it and they will come (Lesson learnt: What counts are branding, traditional advertising and trust).

To reinforce this idea Mackey (2003) adds that for e-business solutions ultimately succeed, when they relieve pain points for the customer. Amazon.com did more than sell books online. Many college students could turn to Amazon as an alternative source when bookstores ran out of texts. Also ebay.com delivered a large choice of products and also put money in people's pockets. Both of these companies solved pain points.

Mackey (2003) notes that channel integration was another hard lesson to learn. In the beginning many brick-and-mortar stores flat out refused to unite their web presence with internal business systems. Many companies went so far as to create a separate web entities fretting about "cannibalization" of existing channels as well as the idea that if the business failed on the internet, it will not affect their brick-and mortar side of the business. Customer focused companies such as Gap worked quickly to adapt systems so that customers can purchase products online and if they changed their minds, could return them easily at retail outlets. This vision gave customers options and elevated e-commerce from a glorified mail order service to a customer value creation and retention opportunity. The bottom line is brick-and-mortar are still learning the valuable lesson that to succeed online, they must integrate their website fully into the business.

Mackey (2003) notes that among the successful integration tales are online baking and online travel booking. Online banking takes away the inconvenience for the customer to get to a bank between $8 \mathrm{am}$ to $5 \mathrm{pm}$ while allowing banks to cut costs and concentrate on improvement and service enhancement.

All in all it looks like for a company to succeed in e-commerce, they must think of positioning themselves properly in the electronic market place in the same way traditional bricks-and-mortar industries do. Click-and-mortar companies should decide what products and services they will provide, what niche they will fill, what business functions they will carry out and what business partners will they use. In addition to this, these click-and-mortar companies must come up with 
sound business models and integrate their brick-and-mortar facilities (if any) with their click and mortar facilities.

New click-and-mortar companies especially pure click-and-mortar companies should be build a brand and add value to their customers as Mackey (2003) puts it relieve "pain points" for the customer.

Small medium enterprises are set to continue to succeed as they continue to redefine their strategy and add value to consumers. According to Joe Sawyer a Forrester senior analyst in an article by McCormick (2000), some of Amazon.com notable strategies are moving beyond selling books and CDs to selling products like electronics, toys and games; building its own network of storage warehouses which helps to save ongoing costs, keep control of the shipping process and keep customers satisfied; and its partnership with local delivery service Kozmo.com which allows faster delivery of orders to customers which adds value to the customers.

\section{CONCLUSIONS}

This article has looked at the way technology has changed the way rural small medium enterprise do silk business in terms. Models like Diffusion of Innovation have used to describe the spread of the internet and e-commerce. With the advent of the internet and information technology, customers are able to access the internet which has numerous goods, services and information 24 hours a day, 7 days a week. Also business models like content, affiliate marketing and personalization as well as new types of goods like digital products have been made possible by technology and e-commerce.

E-commerce has also changed the way value chains have operated in particular disintermediation and re-intermediation. The future of e-commerce for SME has also been looked at and it was found that SME who strategically position themselves on the internet are those that are set to succeed in e-commerce.

\section{REFERENCES}

1. Turban, E., King, D., Lee, J., Warkentin, M., Chung, H. M. (2002) Electronic Commerce A Managerial Perspective, Pearson Education Inc., New Jersey.

2. Singh, J. P. (2007). Culture or Commerce? A Comparative Assessment ofInternational Interactions and Developing Countries at UNESCO, WTO, and Beyond,International studies perspectives, 8(1), pp.36-53.

3. Maupa, H., Nursyamsi, I., Munir, A.R., \& Sulaiman, S. (2012) Periklanan dan Pemasaran melalui E-Mail terhadap PemrosesanInformasi Serta Dampaknya Terhadap Keputusan Pembelian Produk UKMdi Sulawesi Selatan. Jurnal Manajemen "Motivasi".

4. Novak, T. P., Hoffman, D. L., 2001, Profitability of the Web: Business Models and Revenue Streams? [online]

Available: http://elab.vanderbilt.edu/research/papers/pdf/manuscripts/ProfitabiltyOnTheWebJan2001.pdf [2014, June 02]

5. Indonesian Central Bureau of Statistics. 2014. Available: http://www.bps.go.id/

6. Giaglis, G. M., Klein, S., O'Keefe R. M. Disintermediation, Reintermediation, or Cybermediation? The Future of Intermediaries in Electronic Marketplaces [online] Available: http://www.brunel.ac.uk/depts/cs/reports/InterVersion2.pdf [2014, June 02]

7. Nezu, R., 2001, The Impact of E-commerce on Transport [online] Available: http://www.oecd.org/pdf/M00020000/M00020970.pdf [2014, June 02]

8. Nelson, D., 2003, Paid Content Gains Online Viability, Part 2 [online] Available: http://wirelessauthority.com.au/r/article/jsp/sid/13072 [2014, June 02]

9. Varon, E., 2001, The ABCs of B2B [online] Available: http://www.cio.com/research/ec/edit/b2babc.html [2014, June 02] 
10. Rogers, E., 2001, The Communication of Innovation: The need for Internet access multiplies along with [online] Available: http://www.cnn.com/SPECIALS/2000/virtualvillages/story/essays/rogers/ [2014, May 30]

11. Tamplin, E., Marchwick, J., Wanca, C., 1997, The Diffusion of Innovation: The Fortune 100 and the Internet [online] Available: http://www.erikt.com/research/diff/ [2014, May 30]

12. Meck, A., 2001, Shopbots, Powershopping, Powersales: New Forms of Intermediation in ECommerce-An Overview, [online] Available: http://www.wiso.uniaugsburg.de/vwl/institut/paper/203.pdf [2014, May. 30]

13. Web-design-uk.biz, 2002, E-commerce definition, [online] Available: http://www.web-designuk.biz/ecommerce/ecommerce_definition.htm [2014, May 30]

14. Meck, A., 2001, Shopbots, Powershopping, Powersales: New Forms of Intermediation in ECommerce-An Overview, [online] Available: http://www.wiso.uniaugsburg.de/vwl/institut/paper/203.pdf [2014, May 30]

15. BusinessTown.com, 2003, Internet-The World Wide Web: Definition of Ecommerce, [online] Available: http://www. http://www.businesstown.com/internet/ecomm-definition.asp [2014, May 30]

16. Mackey, C., 2003, The Evolution of E-business, [online] Available: http://www.darwinmag.com/read/050103/ebiz.html [2014, May 30]

17. Merkow, M., 2002, The Death of e and the birth of the Real New Economy, [online] Available: http://ecommerce.internet.com/news/insights/outlook/article/0,,10535_983841,00.html [2014, June 06]

18. McCormick, G., 2000, Can Amazon.com Sail Through the E-Retail Storm, [online] Available: http://boston.internet.com/news/article.php/340451 [2014, June 06]

19. Frith, C., 2000, The Diffusion of Innovations, [online] Available: http://www.elec.canterbury.ac.nz/MEM/ENMG604/WEB_Piet/Page/Desk\%20Research\%20Web/ 2000\%20Projects/Frith\%20Diffusion\%20of\%20Innovation.doc [2014, June 06] 